Research Article

\title{
Socio-Demographic Profile of Schedule Tribes of Five Integrated Tribal Development Agency Spots at Kurnool, Andhra Pradesh in India
}

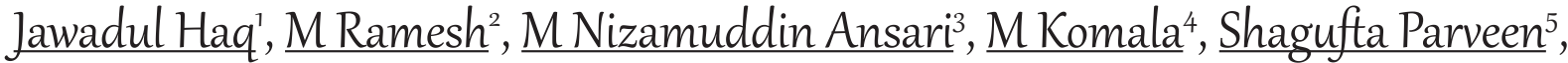 \\ Tamanna Nazli ${ }^{6}$, Abdul Raheem $^{7}$ \\ ${ }^{1,2}$ Research Officer, ${ }^{3,4}$ Research Associate, Clinical Research Unit, Kurnool, Andhra Pradesh, India. \\ ${ }^{5}$ Research Associate, ${ }^{6,7}$ Research Officer, Central Council for Research in Unani Medicine, New Delhi, India. \\ DOI: https://doi.org/10.24321/2454.325X.202108
}

\section{I $\quad \mathbf{N} \quad \mathbf{F} \quad \mathbf{O}$}

Corresponding Author:

Tamanna Nazli, Central Council for Research in Unani Medicine, New Delhi, India.

E-mail Id:

tamanna.ccrum@gmail.com

Orcid Id:

https://orcid.org/0000-0003-4517-3485

How to cite this article:

Haq J, Ramesh M, Ansari MN, Komala M, Parveen S, Nazli T, Raheem A. Socio-Demographic Profile of Schedule Tribes of Five Integrated Tribal Development Agency Spots at Kurnool, Andhra Pradesh in India. Int J Preven Curat Comm Med. 2021;7(2):14-19.

Date of Submission: 2021-05-17

Date of Acceptance: 2021-06-24

\section{$\begin{array}{lllllllllllll}\mathbf{A} & \mathbf{B} & \mathbf{S} & \mathbf{T} & \mathbf{R} & \mathbf{A} & \mathbf{C} & \mathbf{T}\end{array}$}

Background: Tribal population is the second largest in India next to Africa, constituting $8.6 \%$ of total India population. Tribal population have unique physical, socio-economic and cultural environment but most deprived from health care facilities and vulnerable to malnutrition and diseases.

Objective: To study the living condition of tribal people which includes socio-economic, demographic and health status profile along with providing health care facilities to tribes.

Methods: Five Integrated Tribal Development Agency (ITDA) spots which belongs to Chenchu tribe of Kurnool district Andhra Pradesh were adopted. Data was collected through house-to-house survey and in Mobile medical camps in a pre-tested questionnaire provided by CCRUM.

Results: A total of 3174 patients were screened among them 584 person of 130 families were selected for data collection. Majority (93.07\%) were Hindu in the age group 21-30 years (31.6\%), with male preponderance. Education status was fair (42.63\%) population were illiterate. The basis amenities were good, (93.84\%) use piped drinking water, all had open drainage system, $(91.53 \%)$ use LPG, $(89.23 \%)$ household surveys have pucca house, and $(77.69 \%)$ use pit toilet. More than half of them (54.79\%) were married, (70.16\%) adopted permanent sterilization for family planning, 107 females registered when pregnant, majority delivered at hospital (53.44\%), mostly (93.91\%) visited family welfare center, $117(90 \%)$ household don't have government health facility other than $\mathrm{PHC}$ or $\mathrm{MCH}$.

Conclusion: Low-income status, less literacy rate, and unhygienic sanitary conditions were common among Chenchu tribe of Andhra Pradesh. Majority of them (25.87\%) suffered from Musculoskeletal diseases reported to OPD of mobile medical camps.

Keywords: Tribal, Household Survey, Mobile Medical Camps, Scheduled Tribes, Unani 


\section{Introduction}

Over 104 million tribal people spread across 705 tribes live in India. The constitution of India has given special status to the Scheduled Tribes (ST) that contribute $8.6 \%$ of total population. ${ }^{1,2}$ From 5 th five-year plan onwards, tribal development gathered momentum with the introduction of a Tribal sub plan approach. Under this approach Andhra Pradesh has identified 10 areas having concentration of tribal in a continuous area, special development agencies like Integrated Tribal Development Agencies (ITDAs) have been created for overall tribal development in these areas. ${ }^{3}$

Andhra Pradesh has 9 ITDA's covering Srikakulam, Vijayanagaram, Vishakhapatnam, West Godavari, East Godavari, Kurnool, Kadapa, Chittor, Ananthapur, Nellore, Prakasam, Krishna, Guntur districts. ${ }^{3}$ As per 2011 the population of Andhra Pradesh was 49.6 million out of which 2.74 million were Tribal constituting around 5.53\% of total population. ${ }^{3,5}$ Kurnool has a total of 18,105 (2.7\%) of households, total population 82,831 (3.1\%), with total tribal male population of 42,052 (50.8\%) and female 40,799 $(49.2 \%)$. Around $13 \%$ of the total tribal population in the state resides in urban areas. Government of Andhra Pradesh has 5-PTG primitive tribal groups in which Chenchus is one of them. ${ }^{3}$

The present study is to present the analysis and observation of the household surveys and conducted mobile medical camps in the ITDA spots under TSP in Kurnool district of Andhra Pradesh are mainly chenchu tribe in Nandikotkur Chenchu Colony, Velugodu Chenchu Colony, Bairluty Gudem, Siddhapuram, where the tribals reside near the Nallamalla hills and forest area and sugalis in Sugalithanda of Kurnool, Andhra Pradesh.

\section{Methodology}

The data was collected from household survey and mobile medical camps in the five ITDA spots under TSP in Kurnool district of Andhra Pradesh conducted during August 2019 to December 2019 by Clinical Research Unit, Kurnool, Andhra Pradesh. Initially a good company was established with the social workers, government teachers, and head of the tribes who works for the benefits and upliftment of the tribes in the allocated spots, the detail are given in Table 3.

Importance of the study was explained to them \& sought their support in smooth conduction of the house hold survey as well as medical camps. A few houses were randomly selected in all the allotted spots for survey. A semi structured questionnaire allotted by CCRUM was used to collect information from all the houses which includes socio economic, demographic \& health profile particulars like age, sex, area, caste, religion, income status, literacy, occupation, martial, health problems, sanitation \& hygiene conditions and health facilities. Interview method of data collection was used to collect information. Mobile medical camps were also conducted in all the spots 3 days a week and there by collected the data obtained from OPD record.

\section{Results}

Table I.Distribution of Patients in various Adopted spots

\begin{tabular}{|c|c|c|}
\hline Name of the pocket & $\begin{array}{c}\text { Patient } \\
\text { registered }\end{array}$ & $\begin{array}{c}\text { Percentage } \\
\text { (\%) }\end{array}$ \\
\hline Sugalithanda & 666 & 20.98 \\
\hline $\begin{array}{c}\text { Nandikotkur Chenchu } \\
\text { Colony }\end{array}$ & 666 & 20.98 \\
\hline Velugodu Chenchu Colony & 665 & 20.95 \\
\hline Bairluty gudem & 597 & 18.80 \\
\hline Siddhapuram & 580 & 18.27 \\
\hline
\end{tabular}

Table 2.Demographic Details of the $\mathbf{5 8 4}$ People of I 30 Families

\begin{tabular}{|c|c|c|}
\hline Variables & Number & Percentage (\%) \\
\hline \multicolumn{3}{|l|}{ Age group n (\%) } \\
\hline$<20$ & 82 & 14 \\
\hline $20-30$ & 185 & 31.6 \\
\hline $31-40$ & 120 & 20.54 \\
\hline $41-50$ & 97 & 16.6 \\
\hline $51-60$ & 86 & 14.72 \\
\hline$>60$ & 14 & 2.39 \\
\hline \multicolumn{3}{|l|}{ Gender $(n=584)$} \\
\hline Female & 291 & 49.82 \\
\hline Male & 293 & 50.17 \\
\hline \multicolumn{3}{|c|}{ Religion ( $n=130$ families) } \\
\hline Hinduism & 121 & 93.07 \\
\hline Muslim & 8 & 6.15 \\
\hline Christian & 01 & 0.76 \\
\hline \multicolumn{3}{|c|}{ Marital Status $(n=584)$} \\
\hline Married & 320 & 54.79 \\
\hline Unmarried & 49 & 42.63 \\
\hline Widow & 14 & 2.39 \\
\hline Divorced & 01 & 0.17 \\
\hline \multicolumn{3}{|c|}{ Category ( $n=130$ families) } \\
\hline SC & 01 & 0.76 \\
\hline ST & 111 & 85.38 \\
\hline $\mathrm{OBC}$ & 17 & 13.07 \\
\hline \multicolumn{3}{|c|}{ Educational Status $(n=584)$} \\
\hline Illiterate & 249 & 42.63 \\
\hline Pre-primary & 66 & 11.3 \\
\hline Primary School & 113 & 19.34 \\
\hline
\end{tabular}




\begin{tabular}{|c|c|c|}
\hline High School & 60 & 10.2 \\
\hline Intermediate & 62 & 10.6 \\
\hline $\begin{array}{c}\text { Graduate or } \\
\text { above }\end{array}$ & 34 & 5.8 \\
\hline
\end{tabular}

$\mathrm{SC}=$ scheduled class, $\mathrm{ST}=$ scheduled tribe, $\mathrm{OBC}=0$ ther backward class

A total of 130 houses/ families were surveyed and details of all household members (584 individuals) were collected. Maximum number of people $185(31.6 \%)$ were in the age group of 20-30 years followed by 120 (20.54\%) which were from group of 31-40 years. Older age group of more than 60 years was minimum as only $14(2.39 \%)$ peoples were above 60 while $82(14.0 \%)$ falls under $<20$ years. While 97 $(16.6 \%)$ and $86(14.72 \%)$ of people were from age group 41-50 years and $51-60$ years respectively. Of the 584 people $293(50.17 \%)$ were males and $291(49.82 \%)$ were females (Table 2).

Among surveyed family, majority of family $121(93.07 \%)$ were the followers of Hinduism religion while only $1(0.76 \%)$ was of Christian. A very few families 8 (6.15\%) among them were Muslims, followers of Islam. As far as, marital status is concerned, 320 (54.79\%) were married and 249 $(42.63 \%)$ were never married or single, while widowed were $14(2.39 \%)$ and only $1(0.17 \%)$ was separated or divorced. Among them, majority of the families belongs to Scheduled Tribes 111 (85.38\%) followed by other backward caste $17(13.07 \%)$ and only $1(0.76 \%)$ family belongs to Scheduled Caste.

Education level is classified as primary, pre-primary, middle, secondary, graduate and above graduate. Majority 249 $(42.63 \%)$ of the population were illiterate, while among literate, maximum 113 (19.34\%) were only educated to primary school followed by $66(11.3 \%)$ persons having only pre-primary education. Least of them were graduate or above graduate $34(5.8 \%)$ while $60(10.2 \%)$ and $62(10.6 \%)$ were high school and intermediate respectively (Table 2).

Table 3.Available Facilities among the Surveyed Families

\begin{tabular}{|c|c|c|}
\hline Facilities & $\begin{array}{c}\text { No. of families } \\
\text { (n=130) }\end{array}$ & $\begin{array}{c}\text { Percentage } \\
\text { (\%) }\end{array}$ \\
\hline Drinking water source \\
\hline Piped water & 122 & 93.84 \\
\hline Ground water & 08 & 6.15 \\
\hline Location of source of water \\
\hline Outside the house & 109 & 83.84 \\
\hline Inside the house & 21 & 16.15 \\
\hline Storage of water \\
\hline \multicolumn{2}{|l}{} \\
\hline Present & 130 & 100 \\
\hline
\end{tabular}

\begin{tabular}{|c|c|c|}
\hline $\begin{array}{l}\text { For drinking and } \\
\text { domestic use }\end{array}$ & 122 & 93.84 \\
\hline For drinking only & 08 & 6.15 \\
\hline \multicolumn{3}{|l|}{ Types of House } \\
\hline Pucca House & 116 & 89.23 \\
\hline Kaccha House & 14 & 10.76 \\
\hline \multicolumn{3}{|l|}{ Source of Energy } \\
\hline Electricity & 128 & 98.46 \\
\hline Kerosene & 02 & 1.53 \\
\hline \multicolumn{3}{|l|}{ Fuel for cooking } \\
\hline LPG & 119 & 91.53 \\
\hline Wood/Kerosene & 11 & 8.46 \\
\hline \multicolumn{3}{|l|}{ Toilets } \\
\hline No facility & 29 & 22.30 \\
\hline Pit toilet & 101 & 77.69 \\
\hline \multicolumn{3}{|l|}{ Toilet location } \\
\hline Inside the house & 53 & 40.76 \\
\hline Outside the house & 77 & 59.2 \\
\hline \multicolumn{3}{|l|}{ Drainage system } \\
\hline Open type & 130 & 100 \\
\hline Closed type & 0 & 0 \\
\hline
\end{tabular}

Majority of the families had access of drinking water from piped water 122 (93.84\%); only eight families (6.15\%) get ground water, where location of source of water is outside of house for 109 (83.84\%) families, while only few had source of water inside their house [21 (16.15\%)]. Out of 130 families, every family stores water, among them, 122 (93.84\%) families stored for both drinking and domestic purpose and while only 8 (6.15\%) families stored for only domestic purpose. Among those who used to store water inside house, frequency of changing water is practiced daily among 126 (96.92\%) families, while only 4 (3.07\%) changes stored water weekly and fortnightly. Every house has open drainage system and water get stagnated in it and majority 127 (97.69\%) have arrangement for cleaning stagnated water and a few had no cleaning facility (Table 3).

Majority 116 (89.23\%) families have pucca houses and 14 (10.76\%) are having Kaccha house. 128 (98.46\%) families are using electricity and only 2 (1.53\%) among all used kerosene as source of lighting in their house. 91 (70\%) families among surveyed population have sufficient air and light in rooms and $39(30 \%)$ houses do not have proper ventilation available in their houses. Analysis revealed that 52 (40\%) families have pets and domestic animals which are located outside of the house (Table 3).

A total of 119 (91.53\%) households were using liquid 
petroleum gas and 11 (8.46\%) were using wood/ kerosene for cooking purpose. About 101 (77.69\%) use the pit toilet and 29 (22.30\%) of them had no toilet facility where people go to open field/colony sharing toilets are 77 (59.23\%). Toilet was situated inside the house in 53 (40.76\%) houses. Sixty eight (52.30\%) had no habit of washing hands after using the toilet. 39 (30\%) wash with soap, 7 (5.38\%) wash with ash, 16 (12.30\%) wash with sand.

As far as health status of surveyed tribal population is concerned, among 130 selected families, 125 (96.15\%) families have given information of health education activity in their locality during last one year. 84 (64.61\%) are aware of health education in the health center and the remaining $46(35.38 \%)$ had no information about this. Analysis showed that it was useful to only 82 (63.07\%) families and only few $3(2.30 \%)$ said that it was not useful to them. 117 $(90 \%)$ houses gave information that they don't have any government health facility other than $\mathrm{PHC}$ or $\mathrm{MCH}$ Center. Only $13(10 \%)$ houses availed the facilities at this health institutions. 130 (100\%) household surveys revealed that population has not to pay for any of the laboratory services.

Information regarding family planning and methods of contraception were also collected during the survey. It was observed that most of the couples practiced family planning. Among various methods for family planning, in 92 (70.76\%) permanent sterilization remains the most popular modern contraceptive method has undergone sterilization and in the majority of cases $(n=86,66.15 \%)$, the surgery was planned at government hospital and only a few $(n=6,4.61 \%)$ opted private clinic. While few of the couples practiced spacing methods of contraception. However, there were many ( $n=32,24.61 \%$ ) couples who had not been sterilized.

Of the 130 families, 128 (98.46\%) families had not suffered from any emergency during last one year and only 2 (1.53\%) families have reported that one of the family members suffered from an emergency and medical services are available at the distance of less than one $\mathrm{km}$ from their house.

Number of women who gave information regarding ANC during the survey was 107 . All of them registered themselves and 89 of which had visited family welfare center monthly, 10 quarterly, 5 fortnightly and had taken TT injection, IFA tablets, BP recording and blood examination while 15 never got registered in any health or family welfare center. 97 (82.90\%) houses have awareness of health center in their locality and 20 (17.09\%) informed that they don't have any idea /information. Majority of them had delivered at hospital 62 (53.44\%), at center $44(37.93 \%)$ and at home 10(8.62\%). Delivery was conducted by doctor in 92 (79.31\%) cases, by local dai in 10 (8.62\%) cases, ANM in 10 (8.62\%) cases while by trained dai in $4(3.44 \%)$ cases, from center health worker. Regarding immunization, 110 households (100\%) taken BCG, DPT, polio and booster.
Out of total surveyed houses $(n=130)$ birth has taken place and registered during last one year were 9 (6.92\%) and only $1(0.76 \%)$ death were reported. Birth registration office is located less than 500 meters far from 4 (44.4\%), less than $1 \mathrm{~km}$ from 3 (33.33\%), and more than $1 \mathrm{~km}$ from $2(22.22 \%)$ houses.

In mobile, medical camps a total of 3174 patients were screened in all the spots. In which both Sugalithanda and Nandikotkur Chenchu Colony were 666 (20.98\%), 665 (20.95\%) in Velugodu Chenchu Colony, 597 (18.8\%) in Bairluty gudem and 580 (18.27\%) Siddhapuram. (Table 1) Majority belongs to Hindu religion 2193 (91.97\%), Muslims $240(7.56 \%)$ and least Christians 21 (0.66\%). ST caste were 2677 (84.34\%) and followed by others 429 (13.51\%), SC 68 (21.4\%). Majority of patients belong to middle age group including $31-40$ years $(25.23 \%)$ and $21-30$ years $(20.73 \%)$. Majority of them counting females 1792 (56.45\%) and followed by males 1382 (43.54\%).

Table 4.Age Group Distribution of Registered Patient in the Mobile Health Camps

$(n=3174)$

\begin{tabular}{|c|c|c|}
\hline $\begin{array}{c}\text { Age group (in } \\
\text { years) }\end{array}$ & $\begin{array}{c}\text { Number of } \\
\text { patients }\end{array}$ & Percentage \% \\
\hline Less than 10 & 11 & 0.34 \\
\hline $11-20$ & 395 & 12.44 \\
\hline $21-30$ & 658 & 20.73 \\
\hline $31-40$ & 801 & 25.23 \\
\hline $41-50$ & 571 & 17.98 \\
\hline $51-60$ & 431 & 13.57 \\
\hline $61-70$ & 253 & 7.97 \\
\hline $71-80$ & 49 & 1.54 \\
\hline More than 80 & 5 & 0.15 \\
\hline
\end{tabular}

Majority of people suffered from Amraz-e Izam-wa Mafasil (Musculo-skeletal disorders) 502 (25.87\%), 438 (22.57\%) Amraze Nizam Hazam (Digestive disorders), 236 (12.16\%) Amraze Nizam Tanaffus (Respiratory disorders), 158 (8.14\%) Hummiyat (Fever), 135 (6.95\%) Amraze Nizam Bol (Urinary disorders), 128 (6.59\%) Amraze-Uzn-Anaf-Halaq (ENT), 102 (5.25\%) Amraze Jild (Skin disorders), 60 (3.09\%) with Amraze-Nizam-Aasab-wa-Dimagh (Nervous diseases) and Amraze-Niswan-wa-Qabalath (Gynecological and Obstetrical disorders), 56 (2.88\%) Amraze-Qalb-wa-Dawrane-Khoon (Cardiac disorders), 38 (1.85\%) Surgery, 16 (0.82\%) Amraze Tanasil (Sexual Disorders) and least 11 (0.56\%) were of Amraze-Ain (Ophthalmological diseases).

\section{Discussion}

In this study majority (93.07\%) follow the religion Hinduism, it is similar to other studies also done on tribal people, presiding over Nallamalla hills and forest area. ${ }^{4,9,11,12}$ Majority 
(42.63\%) of the population were illiterate. According to census figures, the literacy rate for ST in India is 59\% while in Andhra Pradesh it is $49.2 \%$ \& in Kurnool district, it is 55\%. It is clear from the above that a slight decrease levels of literacy seen when compared with total tribal literacy. ${ }^{3,11-14}$

Majority of them belongs to low income group 118 (90.76\%), followed by 11 (8.46\%) from the class of $11000-20,000$ income group and only $1(0.76 \%)$ family came from the income group of 21000-30,000. As per planning commission estimates, ST people living below poverty line in 2011-12 were $45.3 \%$ in the rural areas. ${ }^{3,10,12}$ Out of 584 people $50.17 \%$ were males $\& 49.82 \%$ were females. There are not much more differences in male and female ratio as previous studies say that male population is slightly higher than female population. ${ }^{3,11}$

Twenty nine (22.30\%) households had no access to toilet, however, majority (77.69\%) of the household were using pit type of toilet. The use of pit toilet had increased from previous years as evident from previous study was done on ST population with pit latrine facility in 2011 rural (1.5\%) \& urban areas (4.1\%) and no toilet facility for $80.9 \%$ in rural areas $\& 88.8 \%$ urban areas. ${ }^{1,9}$

Majority of people use LPG (91.53\%) in all the spots which has drastically increased from previous years due to continuous efforts of the government in state \& central in development of tribal people as it is evident that LPG used by ST people were $11.6 \%$ in Andhra Pradesh as per 2011 census. ${ }^{1,8}$

Majority had access to drinking water from piped water (93.84\%) which had increased from previous decade as per census 2011 total ST population of Andhra Pradesh using tap water $44 \% .^{1,8}$ Every house had open drainage system (100\%), which is far better from 2011 census where the ST population has $29.8 \%$ and no drainage $70 \%{ }^{1}$

Mostly use electricity as (98.46\%) source of lighting for their house and kerosene $1.53 \%$ in 2011 census of Andhra Pradesh total ST population using electricity as main source were $73.1 \%$ \& kerosene $25.3 \%$. Thus, this is much improvement in the usage of electricity from last decade. ${ }^{1}$

Delivery at hospital (53.44\%) and center (37.93\%) was drastically increased from previous decade as shown in the previous studies where it was conducted mostly at home. ${ }^{6,7}$

Family planning methods of terminal method (tubectomy) $(70.76 \%)$ is also increased but spacing method usage is less which is better than previous years. ${ }^{6,7}$ There are other parameters also which require in depth research knowledge but there is lack of research available exclusively on tribal population.

In mobile medical camps 801 (25.23\%) of people belongs to age group of 31-40 years which shows middle aged persons are more prone to suffer from diseases which may be due to faulty dietary and lifestyle habits (Table 4).

Majority of people suffered from musculoskeletal disorders (25.87\%) and digestive disorders. In the previous studies it was reported that malnutrition/ under nutrition was seen mostly which belongs to digestive disorders. ${ }^{5,14}$ But this study showed that it may be due to change in their lifestyle habits, these may be slightly shift to diseases of musculoskeletal disorders.

\section{Conclusion}

It can be concluded that majority of Scheduled Tribe population living in rural areas were literate but meager were up to higher level of education. The basic amenities available such as source of water, cooking gas, toilets within or outside the house, electricity etc. to households was quite satisfactory except the open drainage system which in turn is not good for the healthy environment among the ST population. It may be suggested that the modification can be made in the policies and programs to make Tribal sub plan schemes more applicable and fruitful in terms education and sanitation.

\section{Acknowledgement}

Authors are greatly indebted to the Ministry of AYUSH, Government of India and Director General of CCRUM, New Delhi for undertaking TSP. Authors are also thankful to all the local Pradhan's and Scheduled Tribe people for their support as well as entire staff of TSP at CRU, Kurnool.

Funding: Central Council for Research Unani Medicine

\section{Conflict of Interest: None}

\section{References}

1. Statistical profile of scheduled tribes in India. Ministry of Tribal affairs, Government of India, New Delhi. 2013. Available from: https://tribal.nic.in/downloads/ Statistics/StatisticalProfileofSTs2013.pdf.

2. Population census, New Delhi. Census organization of India. 2011. Available from: http://censusindia.gov.in.

3. Andhra Pradesh urban Finance and Investment development corporation, Government of Andhra Pradesh. Andhra Pradesh Urban Water Supply and Septage Management Improvement Project - The Asian Infrastructure Investment Bank assisted. Tribal peoples planning frame work, Final Report, September 2018. Available from: https://www.aiib.org/en/projects/ details/2018/approved/_download/India/AllBAPUWSSMIP-TPPF-Final-Report-20-Septmeber-2018-2. pdf.

4. Rao KM, Kumar RH, Krishna S, Bhaskar V, Laxmaiah A. Diet and nutrition profile of chenchu population. A Vulnerable Tribe in Telangana and Andhra Pradesh. 
Indian J Med Res. 2015 May;141(5):688-96. [PubMed] [Google Scholar]

5. Dondapati SKS, Karimaddela K. Socio-demographic and health profile of scheduled tribes of velugodu, Andhra Pradesh, India. Int J Community Med Public Health 2016;3(9):2615-20. [Google Scholar]

6. Vithal CP. Socio-economic transformation of a primitive tribal group a study on chenchu in Andhra Pradesh. Man India. 1992 Jun;72(2):189-206. [PubMed] [Google Scholar]

7. Basu SK, Jindal A, Kshatriya GK. The determinants of health seeking behaviour among tribal population of Bastar district, Madhya Pradesh. South Asian Anthropologist. 1990;1:1-6. [Google Scholar]

8. Reddy NNL. Impact assessment of chenchu livelihood Enhancement project. Secunderabad: Centre for people's forestry, 2010.

9. Raju PS, Sudhakar C, Umamchan Ch. Chenchu and socio transformation a study of a primitive tribe in Kurnool district of Andhra Pradesh. Anthropologist. 2009;11:167-72. [Google Scholar]

10. Report of the export group to review the methodology for estimation of poverty. New Delhi planning commission, India. November, 2009.

11. Indian Tribal Welfare and Development, Annual Report, New Delhi. The Ministry of Tribal Affairs 2014-15. Available from: https://tribal.nic.in/downloads/ Statistics/AnnualReport/AnnualReport2014-15.pdf.

12. Makwana RH. An impact of tribal sub-plan scheme on tribal community: a sociological study. Int J Dev Res. 2017;07(7):13879-86.

13. Dora ES. Tribal education: a case study of Gangaram Ashram high school in Warangal district. Int J Humanit Soc Sci. 2017;03(6):347-54.

14. Sreenivasa Rao J, Shivudu G, Panda H, Kalyan Reddy P. Livelihood Strategies resource and nutritional status of forest dependent primitive tribes Chenchu in Andhra Pradesh and Telangana states. Nutri Food Sci Int J. 2019;8(2):1-9. 